\title{
DEVELOPMENT OF A LOCAL MACHINE FOR WINNOWING AND GRADING FLAX SEEDS
}

\author{
Arafa, G. K. * ${ }^{* *} \quad$ M.T. Ebaid * H. A. El-Gendy* \\ ABSTRACT
}

The aim of this investigation is to improve seed cleaner for better clean and grade by using physical and mechanical properties of flax seeds (Sakha 2 -variety). The developed machine was constructed and tested at a private workshop in Kalubia Governorate to clean and grad flax seeds. The performance of the cleaning and grading machine was carried out to investigate some engineering parameters such as: three different feed rates of 1000, 1200 and $1400 \mathrm{~kg} / \mathrm{h}$., four different mesh hole sizes of 0.5, 1.1, 2.5 and $3.0 \mathrm{~mm}$ and four different vibration frequencies of 40, 70, 100 and $130 \mathrm{~Hz}$. physical and mechanical properties of fax seeds under study, purity and grading efficiency were studied to evaluate the performance of developed cleaning and grading machine.

The main results in the present study can be summarized as follows:-

- Physical properties of flax seeds: length $(L)$, width $(W)$, and thickness (T) were 4.38, 2.2, and $0.72 \mathrm{~mm}$, respectively, volume (V) $3.631 \mathrm{~mm}^{3}$, geometric diameter $(D g) 1.906 \mathrm{~mm}$, arithmetic diameter $(D a) 2.44 \mathrm{~mm}$, percentage of sphericity (S) $43.52 \%$, bulk density $(B d) 0.640 \mathrm{~kg} / \mathrm{m}^{3}$, flat surface area $\left(A_{f}\right) 7.56 \mathrm{~mm}^{2}$ transverse surface area $\left(A_{t}\right) 1.24 \mathrm{~mm}^{2}$ mass of 1000-seeds (Km)10 g and optimum moisture content (M.C) of $12.5 \%$ for flax seeds .

- Mechanical properties of flax seeds: the friction angle ( $\Psi)$ between stainless, metal and wood surface and flax seeds was 22, 34, and 40 degree, respectively, coefficient of friction for stainless, metal, and wood surface was $0.404,0.675$, and 0.839, respectively, the angle of repose $(\theta)$ was 30 degree, the terminal velocity $\left(T_{v}\right)$ value to suspended flax grain (Sakha 2 - variety) was $22 \mathrm{~m} / \mathrm{s}$. and hardness of flax seeds was $11.02 \mathrm{~N}$.

- The higher seed purity was $99.33 \%$ and higher grading efficiency was $99.69 \%$ were reached using vibration frequency of $130 \mathrm{~Hz}$, mesh hole size of $3 \mathrm{~mm}$, feed rate of $1400 \mathrm{~kg} / \mathrm{h}$ and moisture content of $12.5 \%$.

\footnotetext{
* Senior Research, Agric. Eng. Res. Inst., Agric. Res. Center, Giza, Dokki, Egypt.

** Research, Agric. Eng. Res. Inst., Agric. Res. Center, Giza, Dokki, Egypt.
} 


\section{INTRODUCTION}

$\mathrm{F}$ lax had been cultivated by ancient Egyptians science 5000 years ago. Flax considers the most important economic oil and fiber crops in the world as well as in Egypt. The flax plays an important role in natural economy due to export and local industry. Flax is usually grown as a dual purposes crop, for the production of fiber extracted from straw and oil obtained from seeds. In Egypt, flax cultivated area was about 35700 feddans* yearly, each feddan produced about 4 ton straw and $825 \mathrm{~kg}$ seeds, (Statistical year book,2003). The physical and mechanical properties of flax seeds play an important role in problems associated with design or development of sieve unit, a specific machine, handling, cleaning and storage. Cleaning and grading of flax seeds are considered the most important topic of flax post harvest. Cleaning and grading are the most important operations, cleaning operation is to separate flax seeds from straw, chaff, broken and weed seed, while grading operation is classifying seeds into uniform categories having the similar properties. It is also reducing the problems during planting, cultivating, seed storage and drying. Harmond et al. (1965) reported that the size of an object determines how much space can be occupied and it can be described in terms of length, width and thickness. They added also that the size is also important in selection or design of disks for precision planting and in proper adjustment of clearances and screen openings in combining. Mohsenin (1986) mentioned that the physical properties of material such as shape, size, volume, and surface area, are important in many problems associated with design or development of specific machine, analysis of the behavior of the product in handling of the material, stress distribution in the material under load, electrostatic separation of grain, light reflectance and color evaluation. One of the important design parameters in conveying of solid materials by air or water in the assumption for the shape of the materials. Accurate estimates of the frontal area and the related diameters are essential for the determination of terminal velocity, drag coefficient, and Reynold number. Awady and EL-Sayed (1994) stated that when air stream is used for separation of product from its associated foreign materials, a knowledge of terminal

*1 fed.=0.42 ha. 
velocity of all the particles is involved. For these reasons, terminal velocity has been used as an important aerodynamic characteristic of materials in such applications an pneumatic conveying and separation from foreign materials. Soliman (1994) studied the effect of moisture content on angle of repose of paddy rice. He mentioned that the dynamic angle of repose is one of the mechanical properties needed for the design of material handling system and storage facilities for rice products. Nigrini et al. (1994) mentioned that the vibratory seed cleaner is considered as an efficient apparatus to achieve clean and grader small seeds of higher quality. Abd El-Ghany (2001) mentioned that increasing feed rate for oil crop from 1200, 1400, 1600 and $1800 \mathrm{~kg} / \mathrm{h}$. decreased the stripping efficiency from 97.31, 95.76, 93.94 and $92.23 \%$ respectively, at drum speed of $300 \mathrm{rpm}$. $(4.39 \mathrm{~m} / \mathrm{s})$ and moisture content of $13.15 \%$. Increasing feed rate from 1200, 1400, 1600 and $1800 \mathrm{~kg} / \mathrm{h}$ increased the percentage of machine capacity from $70.05,97.31,98.48$ and $99.75 \%$ respectively, at moisture content of $13.15 \%$.El-Ashary et al. (2003) cleared that the unthreshed flax seed losses decreased by decreasing seed moisture content. Decreasing flax seeds moisture content from18.15 to $12.05 \%$ tends to increase threshing capacity from 2.23 to $3.06 \mathrm{t} / \mathrm{h}$. from 2.95 to $6.87 \mathrm{t} / \mathrm{h}$. and from 0.19 to $0.48 \mathrm{t} / \mathrm{h}$. for complete, partial mechanized and conventional system, respectively. Also the energy requirements decreased by decreasing seed moisture content. Amin (2003) said that the sieving time, cell shape, and oscillating speed were the main factors that affected the separation efficiency. This efficiency increased by increasing sieving times and oscillating speed rpm. ElGayar (2005) mentioned that there was insignificant differences between the mesh hole size level, the seed moisture content levels, the initial sample weight levels, the vibration frequency and the interaction between these factors level due to purity and grading.

In Egypt the methods of threshing flax are done manually and threshed seeds have weed seeds, undesired seeds, fungal bodies, green leaves, chaff, straw and dust. Then the winnowed of flax seeds is necessary for cleaning by winnowing machine.

So the aim of this study is: 
1- To study the physical and mechanical properties of Egyptian variety of flax seeds (v. Sakha 2), these properties provide data base, consequently it can be used as a guide in seed production and post harvesting operation.

2- To obtain the engineering parameters of the suitable separation and grading machine from physical and mechanical properties of the threshed materials.

\section{MATERIAL AND METHODS}

In the present study, the winnowing machine was modified and tested at a private workshop in Kalubia Governorate for cleaning and grading flax seeds. The developed machine consists of frame, hopper, electric motor and oscillating dual-screen assembly as shown in Fig. (1). The frame was supported on four legs. Power transfer from the electric motor to oscillating screen. General specifications of machine are: overall (length $1428 \mathrm{~mm}$, width $570 \mathrm{~mm}$, height $1210 \mathrm{~mm})$, power of $0.3 \mathrm{hp}(0.225 \mathrm{~kW})$, labor requirement 1-2 man, easy operation, minimum adjustments, reduced repairs and maintenance problems. Construction includes $1 \mathrm{~mm}$ sheet metal and 30x30x3 angle iron.

\section{1- Machine specifications and description:}

Frame: Made of angle steel sections 30x30x3 mm

Hopper: Made of steel metal of $1 \mathrm{~mm}$ thickness and angle iron steel section 30x30x3 mm.

Sieves: Made of steel metal of $1.5 \mathrm{~mm}$ thickness. They consists of four wire mesh holes having of 0.5, 1.1, 2.5 and $3.0 \mathrm{~mm}$ were located in screen assembly to remove impurities to pass underneath (the shape and dimensions of the used mesh were chosen according to the pervious measured physical and mechanical properties of flax seeds).

Electric motor: An electric motor power of $0.3 \mathrm{hp}(0.225 \mathrm{~kW})$ was used at 1500 r.p.m.

\section{2-Modification recommendation:}

- To use machine in cleaning: it was used as it is (before modification).

- To use machine in winnowing and grading: 1- Remove fan

2- Increase the number of screen from two to four screens.

3 - Increase the execentric speed to suit cleaning and grading process. 


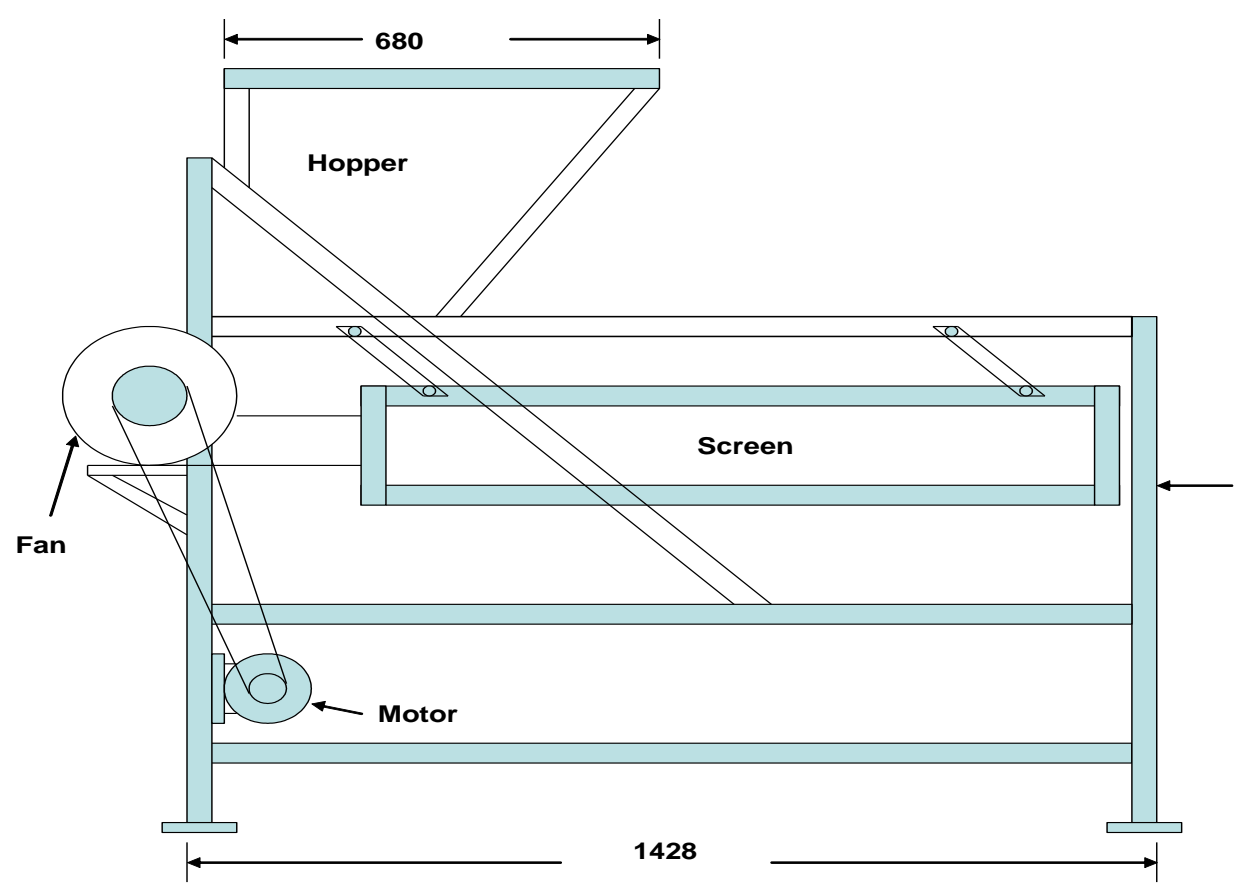

Main frame

a) Before modification

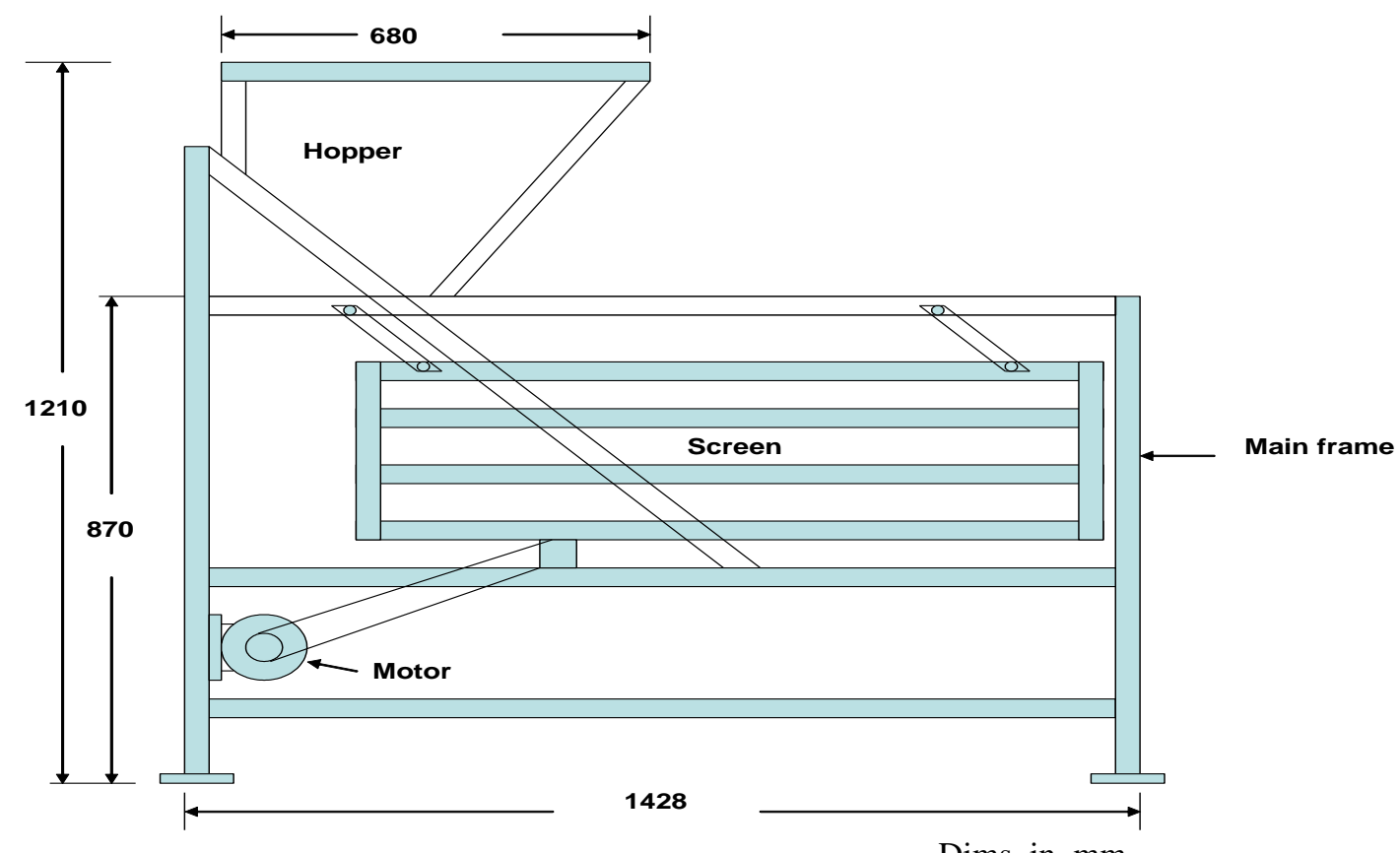

Dims. in. $\mathrm{mm}$

b) After modification

Fig. (1): Sketch of modified winnowing and grading machine. 


\section{3- Determination of physical and mechanical properties of flax seeds}

\section{used in investigation:}

500 flax seeds (v. Sakha 2) were taken to in random determine the physical and mechanical properties. Average plant height, was $121 \mathrm{~cm}$. Fiber represent $19.5 \%$, and oil in seeds $42.5 \%$, producing about 4 ton/feddan from straw and $825 \mathrm{~kg} /$ feddan from seeds, and capsules diameter $0.92 \mathrm{~cm}$. (Statistical year book,2003). All treatments were replicated five times to give more reliable average. Table (1) shows the mean, standard deviation, and coefficient of variance of length, width, thickness, mass of 1000-seeds, volume, percentage of sphericity, geometric diameter, arithmetic diameter, flat surface area transverse surface area, bulk density, and moisture content for flax seeds.

Table 1: Physical properties of flax seeds.

\begin{tabular}{|c|c|c|c|}
\hline Seed parameter & Mean & S.D & C.V \% \\
\hline L & 4.38 & 0.28 & 0.071 \\
\hline W & 2.2 & 0.22 & 0.04 \\
\hline T & 0.72 & 0.09 & 0.006 \\
\hline V & 3.631 & 0.51 & 0.25 \\
\hline S & 43.52 & 2.40 & 5.38 \\
\hline Dg & 1.906 & 0.109 & 0.011 \\
\hline Da & 2.44 & 0.108 & 0.010 \\
\hline Af & 7.56 & 0.94 & 0.817 \\
\hline At & 1.24 & 0.167 & 0.026 \\
\hline Km & 10 & - & - \\
\hline Bd & 0.640 & - & - \\
\hline M.C & 12.5 & - & - \\
\hline
\end{tabular}

Where:-
S.D = standard deviation,
C. $\mathrm{V}=$ coefficient of variance $\%$
$\mathrm{L}=$ length, $\mathrm{mm}$
$\mathrm{W}=$ width, $\mathrm{mm}$
$\mathrm{T}=$ thickness $\mathrm{mm}$,
$\mathrm{Km}=$ mass of 1000-seeds, $\mathrm{g}$
$\mathrm{V}=$ volume $\mathrm{mm}^{3}$,
$\mathrm{S}=$ percentage of sphericity $\%$,
$\mathrm{Dg}=$ geometric diameter $\mathrm{mm}$,
$\mathrm{Da}=$ arithmetic diameter $\mathrm{mm}$
$\mathrm{A}_{\mathrm{t}}=$ transverse surface area $\mathrm{mm}^{2}$
$\mathrm{A}_{\mathrm{f}}=$ flat surface area $\mathrm{mm}^{2}$
$\mathrm{Bd}=$ bulk density $\mathrm{kg} / \mathrm{m}^{3}$, and
M.C. $=$ moisture content $\%$. 
The following relations were used according to El-Raie et al. (1996).

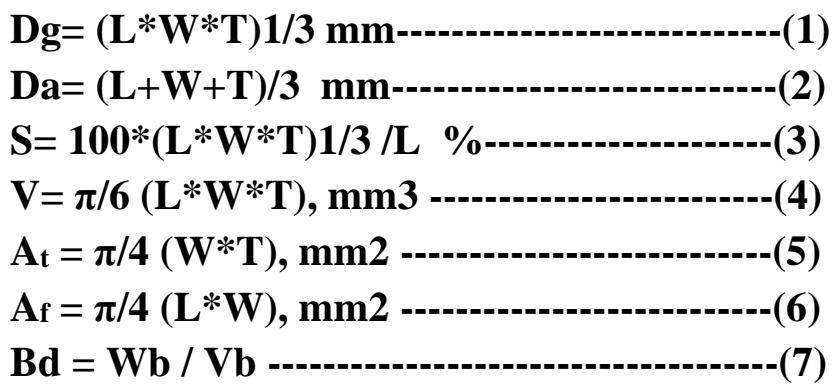

Using the mean values, the following general equations can be written to express the relationship between, length, width, and thickness:-

Flax seeds (v. Sakha 2) $\mathrm{L}=1.99 \mathrm{~W}=6.1 \mathrm{~T}$.

One of the most common and accurate methods being the prediction of these values from the measurements of length, width, and thickness of the product. In the present study, the formulae (1), (2), (4), (5), and (6) were used to determine these values for all seeds of samples. The results were analyzed statistically, and the following general equations can be written to express the relationships between the terms $\mathrm{L}, \mathrm{W}, \mathrm{T}$ and $\mathrm{V}, \mathrm{A}_{\mathrm{f}}, \mathrm{A}_{\mathrm{t}}, \mathrm{Dg}$, Da for flax seeds (Sakha 2 - variety).

$$
\begin{aligned}
& \mathrm{V}=0.043 \mathrm{L3}=0.34 \mathrm{W3}=9.73 \mathrm{T3} \\
& A_{t}=0.065 \text { L2 }=0.26 \text { W2 }=2.39 \text { T2 - } \\
& A_{f}=0.39 \mathrm{~L} 2=1.56 \mathrm{~W} 2=14.58 \mathrm{~T} 2 \\
& \mathrm{Dg}=0.44 \mathrm{~L}=0.87 \mathrm{~W}=2.65 \mathrm{~T} \\
& \mathrm{Da}=0.56 \mathrm{~L}=1.11 \mathrm{~W}=3.39 \mathrm{~T}
\end{aligned}
$$

The main advantage of the equations (9) to (13) is that, the volume or the flat or transverse surface area or geometric or arithmetic diameter of a seed can be predicted with reasonable accuracy from a measurement of any one of the three principal dimensions of $\mathrm{L}, \mathrm{W}, \mathrm{T}$.

Also friction angle, coefficient of friction, angle of repose, and hardness for flax seeds reported are shown in table 2 . 
Table 2: Mechanical properties of flax seeds.

\begin{tabular}{|l|l|}
\hline \multicolumn{1}{|c|}{ Mechanical properties } & \multicolumn{1}{|c|}{ Flax seeds } \\
\hline $\begin{array}{l}\text { Friction angle } \Psi \\
\text { for stainless surface } \\
\text { for metal surface } \\
\text { for wood surface }\end{array}$ & $\begin{array}{l}22 \text { degree } \\
34 \text { degree } \\
40 \text { degree }\end{array}$ \\
\hline - Coefficient of friction & \\
$\quad$ for stainless surface & 0.404 \\
for metal surface & 0.675 \\
for wood surface & 0.839 \\
\hline Angle of repose $\theta$ & 30 degree. \\
\hline Hardness & $11.02 \mathrm{~N}$. \\
\hline
\end{tabular}

Friction angle (degree), coefficient of friction, angle of repose (degree), hardness $(\mathrm{N})$, and terminal velocity $(\mathrm{m} / \mathrm{s})$ was measured to determine the mechanical properties as follows:-

\section{A) Friction angle, degree ( $\Psi)$.}

It was measured between seeds and stainless, metal, and wood surfaces. 1000 sample of flax seeds were used.

\section{B) Angle of repose, degree $(\theta)$.}

It is the angle between the horizontal base and the inclined side of the formed cone due to free fall of seeds sample. The horizontal base of the cone $(\mathrm{x})$ and its height $(\mathrm{L})$ were measured by a ruler and the repose angle can be calculated as follows:-

$$
\tan \theta=L / 0.5 x
$$

\section{C) Terminal velocity $\left(V_{t}\right) \mathrm{m} / \mathrm{s}$.}

The terminal velocity for seeds was determined by using floating apparatus (Source of manufacture in Japan, Electricity source of power, Work theory by vacuum, Maximum measuring in $25 \mathrm{~m} / \mathrm{s}$ and accuracy $0.1 \mathrm{~m} / \mathrm{s}$ ). The terminal velocity of the air stream at which the body remains suspended is know as the terminal velocity of critical velocity.

\section{4- Factors effect on cleaning and grading effectiveness for machine:}

The following parameters were considered during the cleaning and grading machine testing.

A) Feed rate: Three different feeding rates were tested 1000, 1200 and $1400 \mathrm{~kg} / \mathrm{h}$. 
B)Vibration frequency: Four different vibration frequencies of 40, 70, 100 and $130 \mathrm{~Hz}$.

C) Mesh hole size: Four different mesh hole sizes of 0.5, 1.1, 2.5 and 3.0 $\mathrm{mm}$.

\section{5- Calculations:}

A) Purity (P):

$$
\mathbf{P}=\frac{\text { Weight of cleaned seeds }}{\text { Total weight of sample }} \times 100
$$

B) Grading efficiency (Ge):

The following relation was used according to El-Gayar (2005)

$$
\mathbf{G e}=\frac{W a}{W a+W_{c}} \times 100
$$

Where:- Wa: $W$ Weight of seed recovered in product, $\mathrm{kg}$ and

Wc: Weight of seed in the reject, $\mathrm{kg}$.

\section{1- Dimensions of flax seeds:}

\section{RESULTS AND DISCUSSION}

Grain dimensions used in the experiments are shown in fig. 2. Mean dimensions of flax seeds are as follows:-

length $(\mathrm{L})=4.38 \mathrm{~mm}$, width $(\mathrm{W})=2.2 \mathrm{~mm}$, and thickness $(\mathrm{T})=0.72 \mathrm{~mm}$.

Fig. 2. data indicates that the percentage of frequency is $60 \%$ at mean grain length of about $4.4 \mathrm{~mm}$, for mean grain width of about $2.0 \mathrm{~mm}$ with the percentage of frequency is $49 \%$, and for mean grains thickness of about $0.8 \mathrm{~mm}$ with the percentage of frequency is $85 \%$.

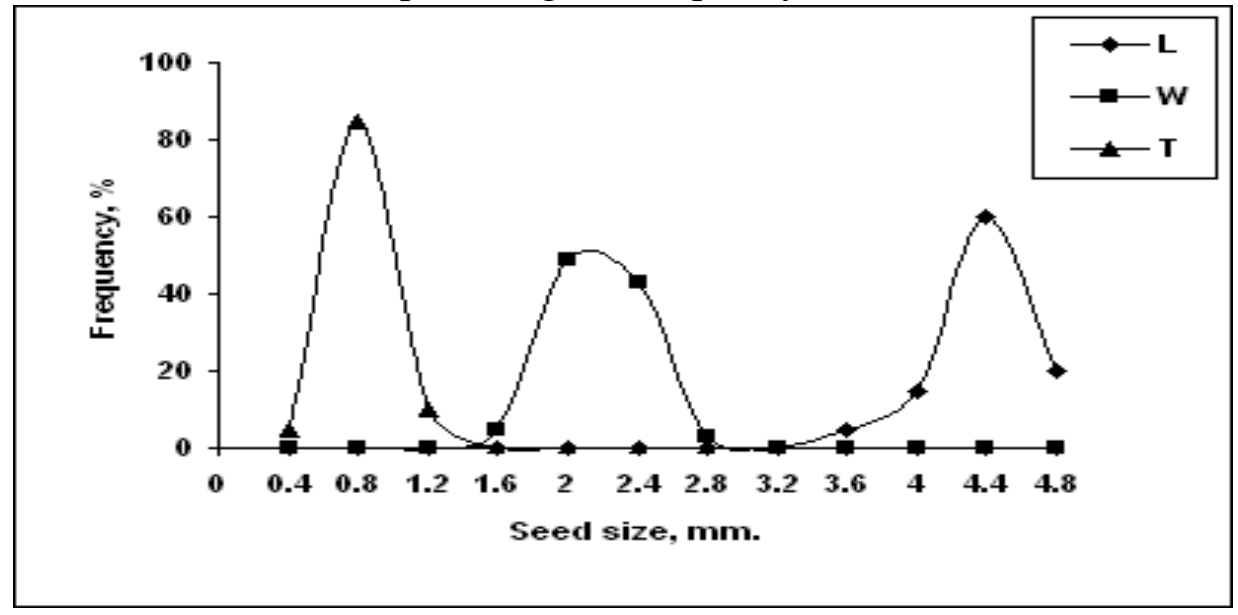

Fig. 2: Frequency of 3 dimensions of flax seeds (v. Sakha 2). 


\section{2- Factors affecting purity.}

\section{2-1 Feed rate}

Fig. (3) shows the effect of feed rate on purity at different mesh hole sizes, vibration frequency of $130 \mathrm{~Hz}$ and moisture content of $12.5 \%$. Purity decreased by increasing feed rate.

It was found that by increasing feed rate from 1000 to $1400 \mathrm{~kg} / \mathrm{h}$. purity decreased from 96.23 to $85.35 \%$ respectively at mesh hole size of $1.1 \mathrm{~mm}$.

From fig. (3) It was found that purity affected by feed rate at mesh hole size of 0.5 and $1.1 \mathrm{~mm}$, but at mesh hole size of 2.5 and $3 \mathrm{~mm}$ there was no effect for feed rate on purity. It refers to at big mesh hole size (2.5 and $3 \mathrm{~mm}$ ) more seed quantities deposited up on the mesh holes, allowing more seed quantity to pass through the holes. The best feed rate was 1400 $\mathrm{kg} / \mathrm{h}$.

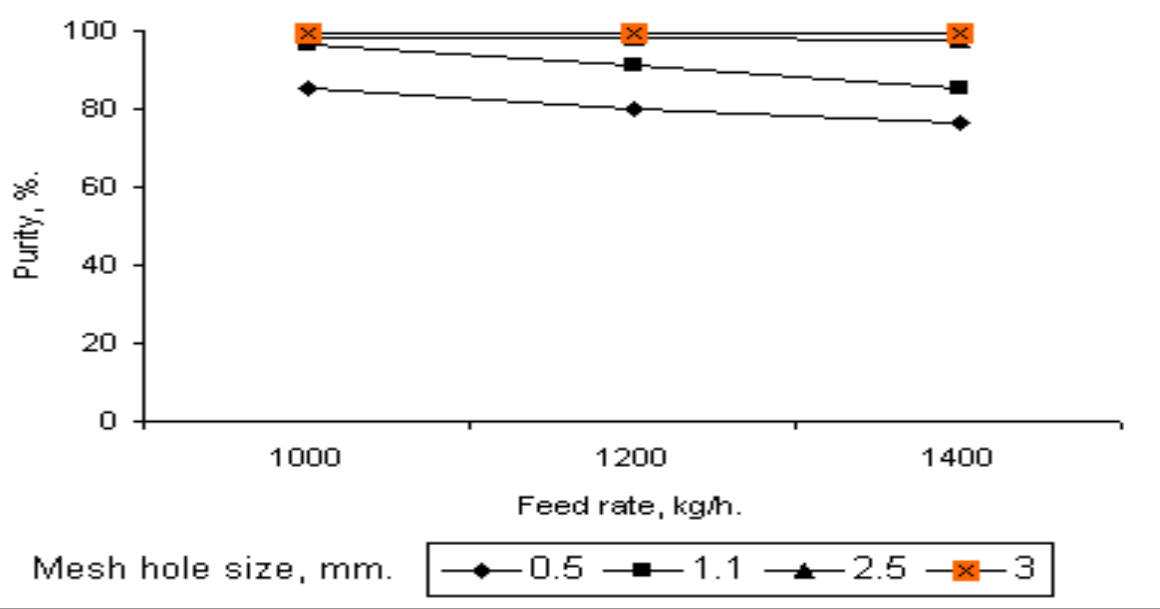

Fig. 3: Effect of feed rate for flax seeds on purity at different at different mesh hole sizes, vibration frequency of $130 \mathrm{~Hz}$ and moisture content of $12.5 \%$.

\section{2-2 Vibration frequency.}

Fig. (4) shows the effect of vibration frequency on purity at different mesh hole sizes, feed rate of $1400 \mathrm{~kg} / \mathrm{h}$ and moisture content of $12.5 \%$. Purity increased by increasing vibration frequency.

It was found that purity increased from 79.73 to $84.51 \%$ as the vibration frequency increased from 40 to $130 \mathrm{~Hz}$, respectively at mesh hole size of $0.5 \mathrm{~mm}$. 
From Fig. (4) by increasing vibration frequency the movement of threshed materials on the sieve increased and there is no chance for impurities to pass thought the grain spout with grains. The best vibration frequency was $130 \mathrm{~Hz}$.

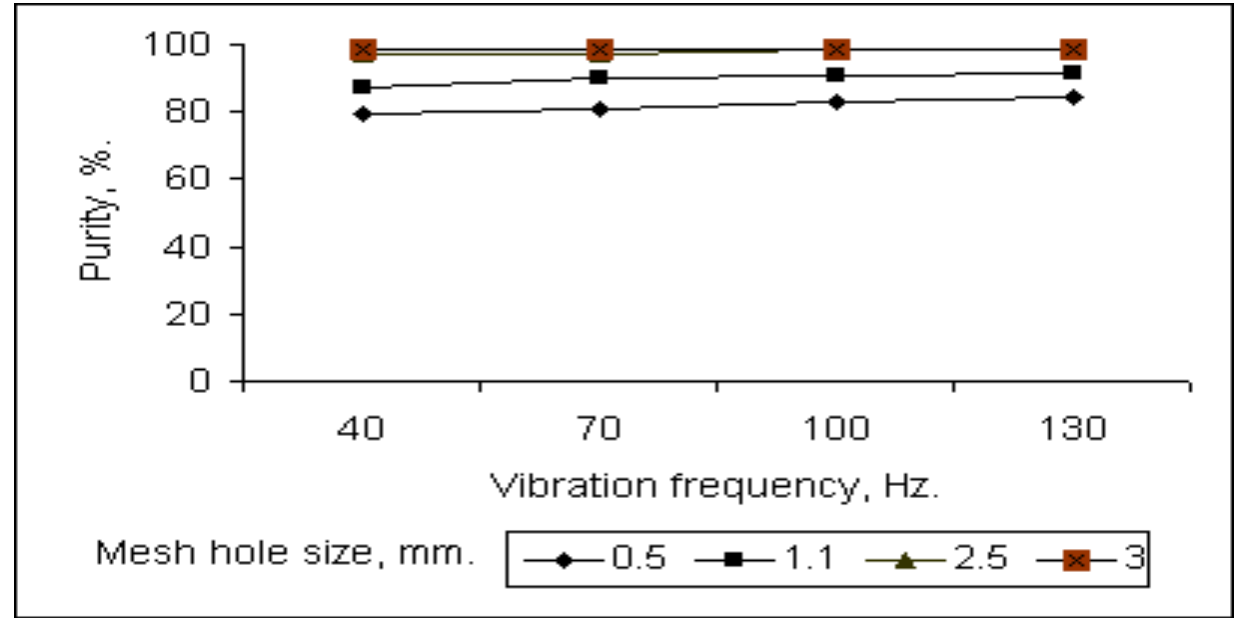

Fig. 4: Effect of vibration frequency on purity at different mesh hole sizes, feed rate of $1400 \mathrm{~kg} / \mathrm{h}$ for flax seeds and moisture content of $12.5 \%$.

\section{2-3Mesh hole size.}

Fig. (5) shows the effect of mesh hole size on purity at different feed rate vibration frequency of $130 \mathrm{~Hz}$ and moisture content of $12.5 \%$. Purity increased by increasing mesh hole size.

It was found as the mesh hole size increased from 0.5 to $3 \mathrm{~mm}$, purity increased from 76.19 to $99.33 \%$, respectively at feed rate of $1400 \mathrm{~kg} / \mathrm{h}$.

It refers to at big mesh hole size more seed quantities deposited up on the mesh holes, allowing more seed quantity to pass through the holes. But at small mesh hole size the threshed materials accumulated on the sieve gave chance to pass straw and impurities through the grain spout which drops with grain. The best mesh hole size was $3 \mathrm{~mm}$. 


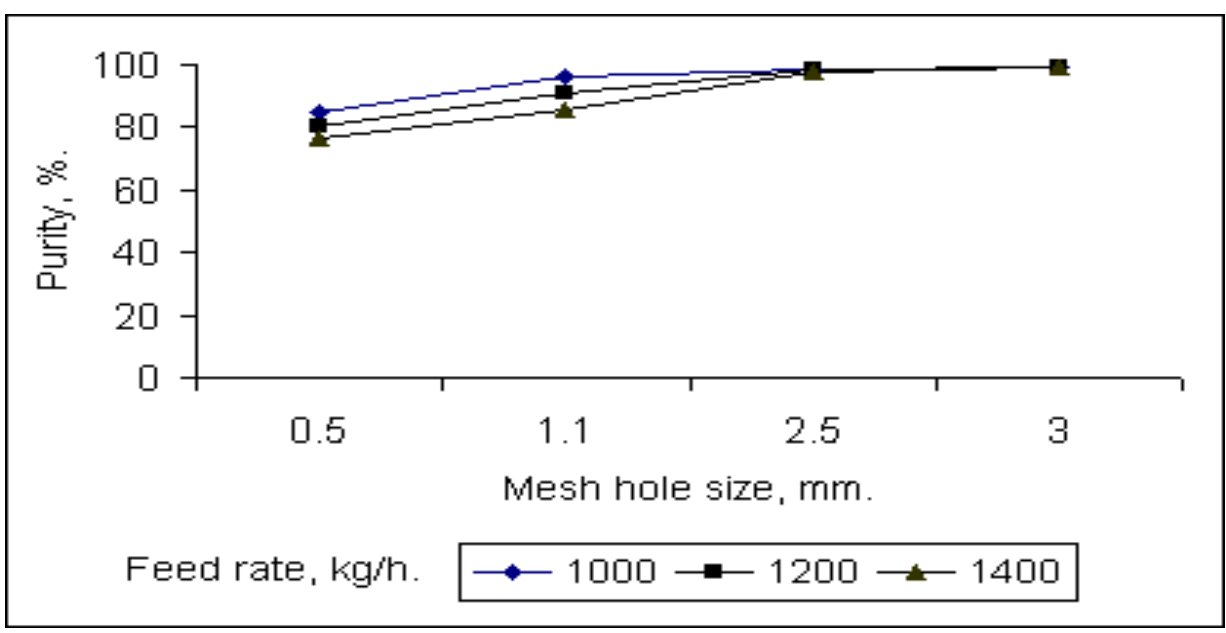

Fig.5: Effect of mesh hole size on purity at different feed rates of flax seeds vibration frequency of $130 \mathrm{~Hz}$ and moisture content of $12.5 \%$.

\section{3- Factors affecting grading efficiency.}

\section{3-1 Feed rate}

Fig. (6) shows the effect of feed rate on grading efficiency at different mesh hole sizes, vibration frequency of $130 \mathrm{~Hz}$ and moisture content of $12.5 \%$. Grading efficiency decreased by increasing feed rate.

From Fig. (6) it was found that the grading efficiency decreased from 65.11 to $20.91 \%$ as the feed rate increased from 1000 to $1400 \mathrm{~kg} / \mathrm{h}$, respectively at mesh hole size of $2.5 \mathrm{~mm}$. But grading efficiency not affected by using mesh hole size of $3 \mathrm{~mm}$. It refers to at big mesh hole size more seed quantities deposited up on the mesh holes, allowing more seed quantity to pass through the holes.

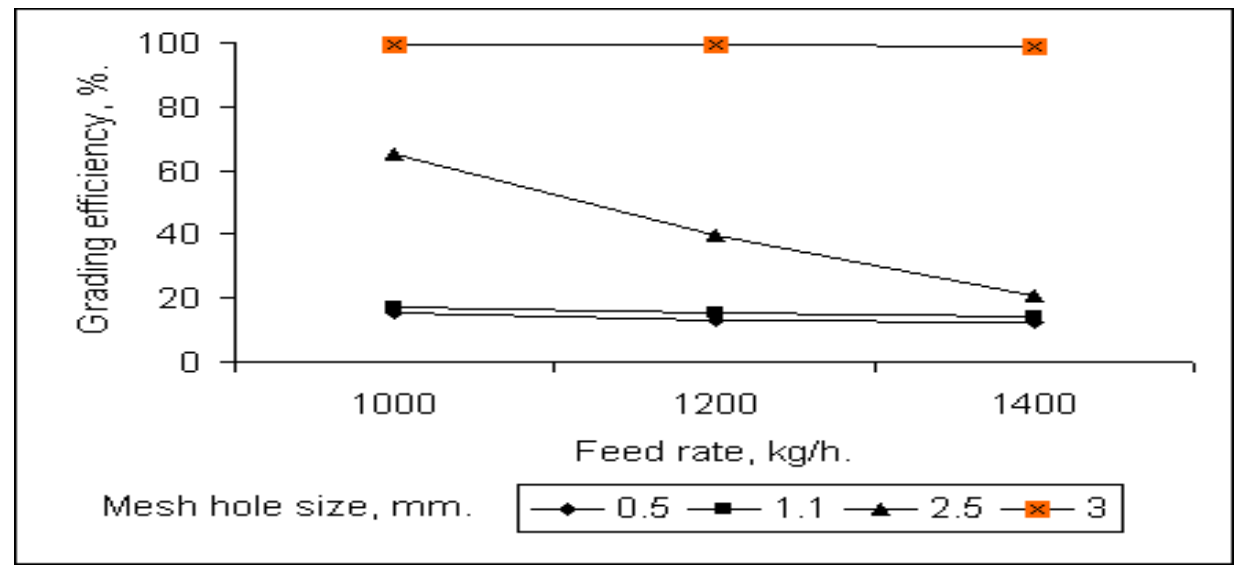

Fig. 6: Effect of feed rate of flax seeds on grading efficiency at different mesh hole sizes, vibration frequency of $130 \mathrm{~Hz}$ and moisture content of $12.5 \%$. 


\section{3-2 Vibration frequency.}

Fig. (7) shows the effect of vibration frequency on grading efficiency at different mesh hole sizes, feed rate of $1400 \mathrm{~kg} / \mathrm{h}$. and moisture content of $12.5 \%$.

It was found that by increasing vibration frequency from 40 to $130 \mathrm{~Hz}$. grading efficiency increased from 93.90 to $99.69 \%$, respectively at mesh hole size of $3 \mathrm{~mm}$.

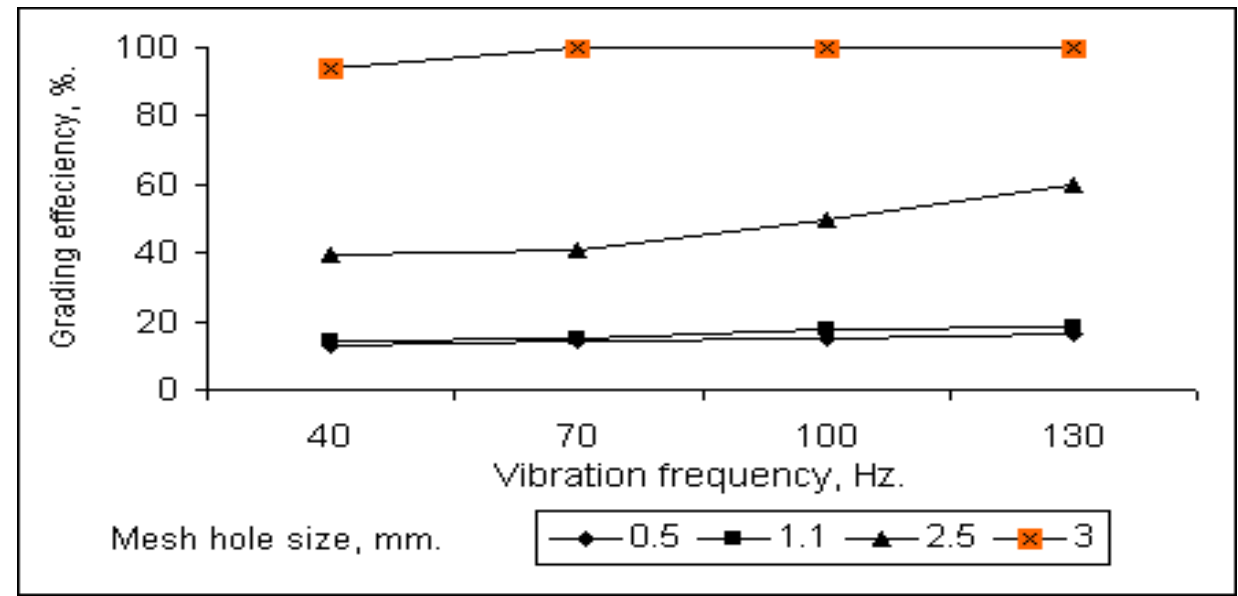

Fig. 7: Effect of vibration frequency on grading efficiency at different mesh hole sizes feed rate of $1400 \mathrm{~kg} / \mathrm{h}$ for flax seeds and moisture content of $12.5 \%$.

\section{3-3Mesh hole size.}

Fig. (8) shows the effect of mesh hole size on grading efficiency at different, feed rates, vibration frequency of $130 \mathrm{~Hz}$. and moisture content of $12.5 \%$.

It was found as the mesh hole size increased from 0.5 to $3 \mathrm{~mm}$, grading efficiency increased from 15.20 to $99.69 \%, 13.30$ to $99.60 \%$ and 12.4 to $99.10 \%$ using feed rate of $1400 \mathrm{~kg} / \mathrm{h}$, respectively. 


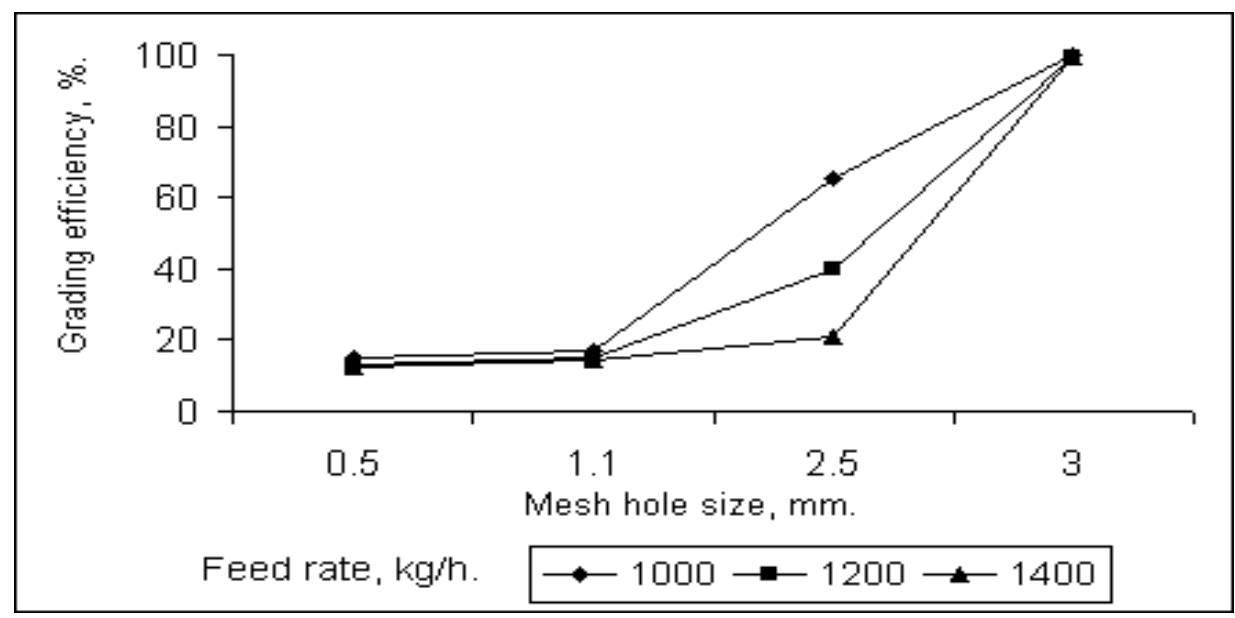

Fig. 8: Effect of mesh hole size on grading efficiency at different feed rates, vibration frequency of $130 \mathrm{~Hz}$. and moisture content of $12.5 \%$.

\section{CONCLUSION}

\section{The main results in this study can be summarized as follows:-}

1- Physical properties of flax seeds: length (L), width (W), and thickness (T) were 4.38, 2.2, and $0.72 \mathrm{~mm}$, respectively , volume (V) $3.631 \mathrm{~mm} 3$, geometric diameter $(\mathrm{Dg}) 1.906 \mathrm{~mm}$, arithmetic diameter (Da) $2.44 \mathrm{~mm}$, percentage of sphericity (S) $43.52 \%$, bulk density (Bd) $0.640 \mathrm{~kg} / \mathrm{m} 3$, flat surface area $\left(\mathrm{A}_{\mathrm{f}}\right) 7.56 \mathrm{~mm} 2$ transverse surface area $\left(\mathrm{A}_{\mathrm{t}}\right) 1.24 \mathrm{~mm} 2$ mass of 1000 -seeds $(\mathrm{Km}) 10 \mathrm{~g}$ and optimum moisture content (MC) of $12.5 \%$ for flax seeds .

2- Mechanical properties of flax seeds: the friction angle $(\Psi)$ between stainless, metal and wood surface and flax seeds was 22, 34, and 40 degree, respectively, coefficient of friction for stainless, metal, and wood surface was $0.404,0.675$, and 0.839 , respectively, the angle of repose $(\theta)$ was 30 degree, the terminal velocity $\left(\mathrm{T}_{\mathrm{v}}\right)$ value to suspended flax grain (v. Sakha 2) was $35 \mathrm{~m} / \mathrm{s}$. and hardness of flax seeds was $11.02 \mathrm{~N}$.

3 - The higher seed purity was $99.33 \%$ and higher grading efficiency was $99.69 \%$ were reached using vibration frequency of $130 \mathrm{~Hz}$, mesh hole size of $3 \mathrm{~mm}$, feed rate of $1400 \mathrm{~kg} / \mathrm{h}$ and moisture content of $12.5 \%$.

\section{LITERATURE CITED}

Abd El-Ghany, H. M. (2001); Developing a thresher machine for oil crops. Ms. C., Fac. Of Ag., Ain Shams U., Egypt.: 66 p. 
Amin, E. E. A. (2003); Effect of some physical and mechanical properties on grading efficiency, the 11th Annual Conference of Misr Society of Agr. Eng. Oct. 2003 :;451-470.

Awady, M. N., and A. S. Sayed, (1994); Separation of peanuts seeds by air stream, MSAE., 11 (1) : 137-147.

El-Gayar, S. M. (2005); Flax seeds cleaning and grading using vibratory apparatus. Misr.J. Ag. Eng., 22(3) : 923-942.

EL-Ashary A.S., A.EL-Rayes, and G.R.Gamea (2003); A comparative study of Flax threshing systems and their efects on yield components quality. Misr.J. Ag. Eng., 20(3) : 691-701.

El-Raie; A.E.S.; N. A. Hendawy and A.Z. Taib, (1996); Study of physical and engineering properties for some agricultural products. Misr. J. Ag. Eng., 13 (1) : 211-226.

Harmond, J. E.; N. R. Brandenburg, and A.J. Louisa, (1965); Physical properties of seed, Trans. Of ASAE., 8 (1) :30-32.

Mohsenin, N. N., (1986); Physical Properties of Plant and Animal Materials, Gordon and Breach Sc. Pub., N. Y. pp. 734.

Nigrini, O C., K. Spilman, Y. J. Wang, D. S. Chung, and Posner (1994); Evaluation of laboratory grain cleaning and separating equpmint. Part II Trans. of the ASAE. 37 (6):1913-1918.

Soliman, N.S. (1994); Effect of moisture content on angle of repose of paddy rice and its products. Misr.J. Ag. Eng. 11(1): 163-173.

Statistical Year book (2003); M. of Agriculture and land Reclamation (in Arabic) : 3-20.

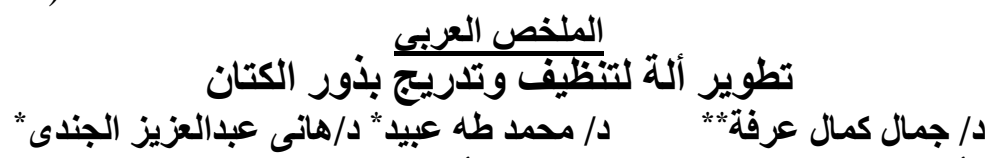

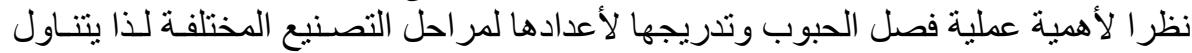

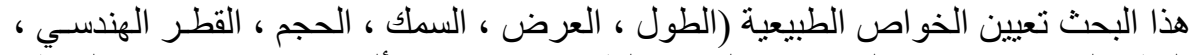

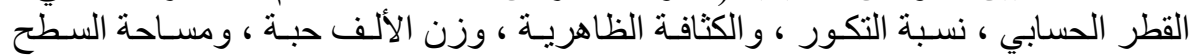

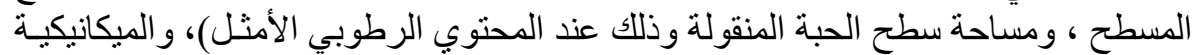

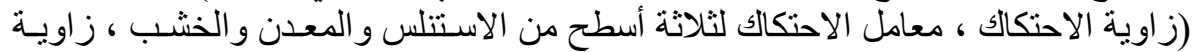

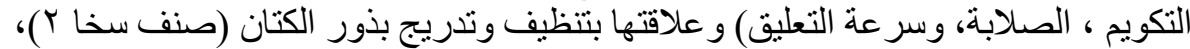

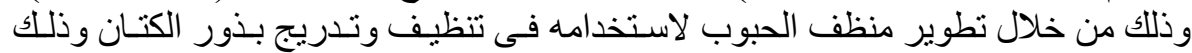

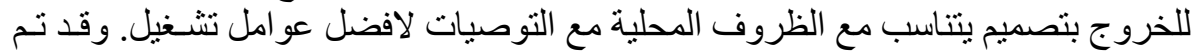

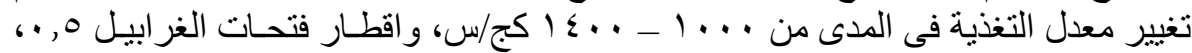

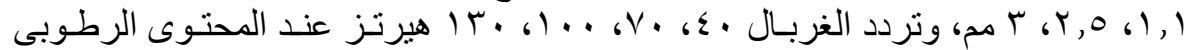

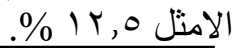

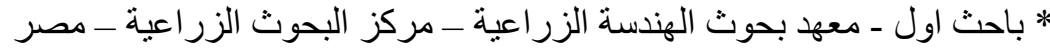

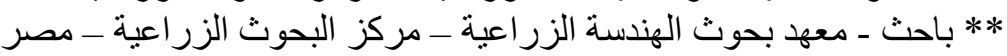


وتم التوصل الى النتائج و التوصيات التالية للحصول على أعلى نسبة نظافـة و أفضـل درجـة

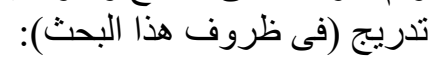

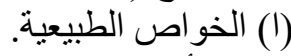

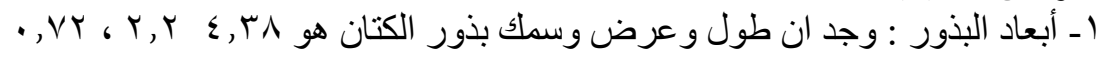

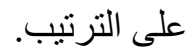

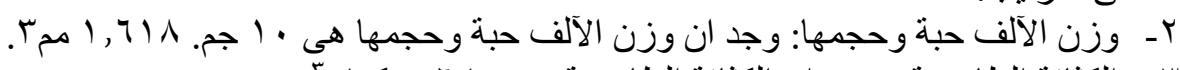

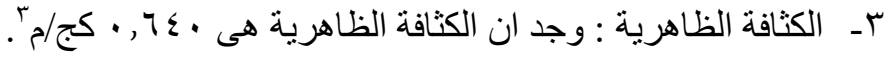

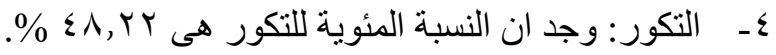

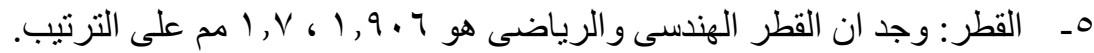

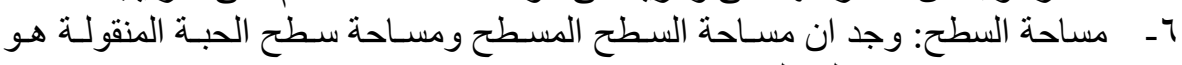

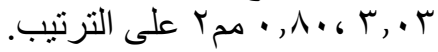

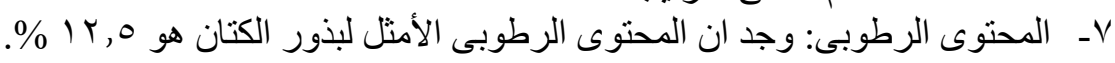

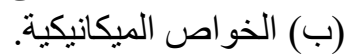

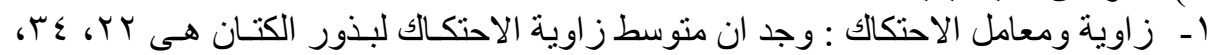

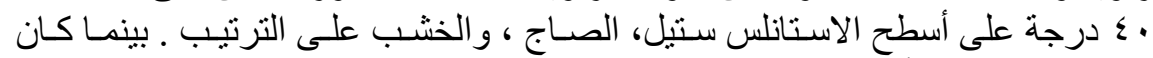

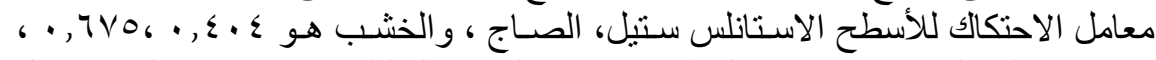

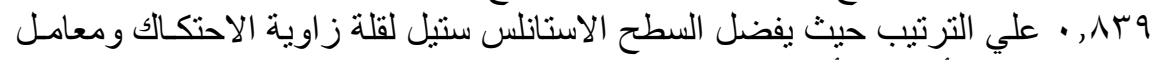

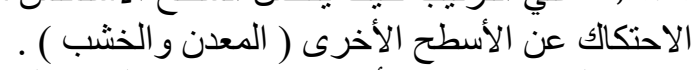

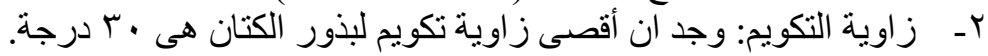

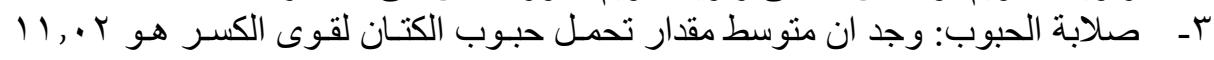
نيوتن. عـ - سر عة التعليق: وجد ان السر عة المناسبة للتخلص من القش و الأتربــة والأجز اء الدقيقة

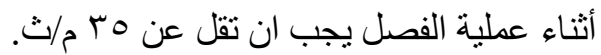
(ج) تم التوصل الى علاقة تربط بين الأبعاد الأساسية للبذور (الطول و العرض و السمك) وهى:

$$
\mathrm{L}=1.99 \mathrm{~W}=6.1 \mathrm{~T}
$$

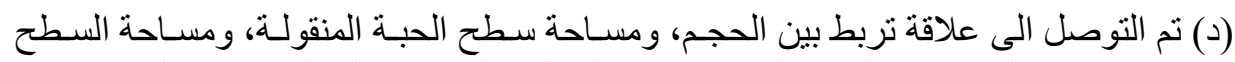

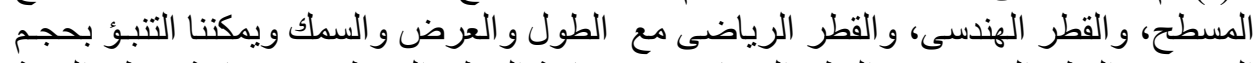

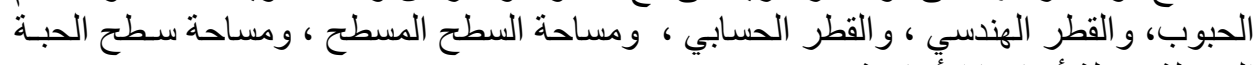

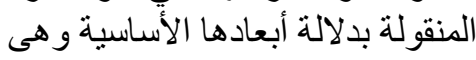

$$
\begin{gathered}
\mathrm{V}=0.043 \mathrm{~L} 3=0.34 \mathrm{~W} 3=9.73 \mathrm{~T} 3 \\
\mathrm{~A}_{\mathrm{t}}=0.065 \mathrm{~L} 2=0.26 \mathrm{~W} 2=2.39 \mathrm{~T} 2 \\
\mathrm{~A}_{\mathrm{f}}=0.39 \mathrm{~L} 2=1.56 \mathrm{~W} 2=14.58 \mathrm{~T} 2 \\
\mathrm{Dg}=0.44 \mathrm{~L}=0.87 \mathrm{~W}=2.65 \mathrm{~T} \\
\mathrm{Da}=0.56 \mathrm{~L}=1.11 \mathrm{~W}=3.39 \mathrm{~T}
\end{gathered}
$$

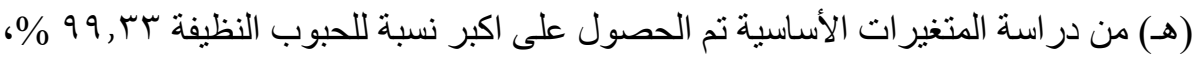

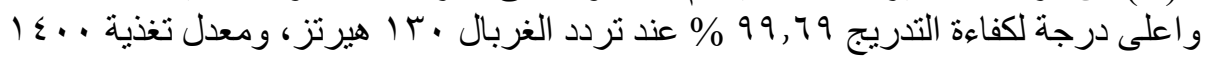

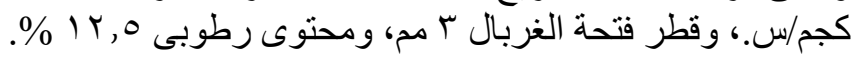

